\title{
The mental health of civilians displaced by armed conflict: an ecological model of refugee distress
}

\author{
K. E. Miller ${ }^{1 *}$ and A. Rasmussen ${ }^{2}$ \\ ${ }^{1}$ War Child Holland, Helmholtzstraat 61, 1098 LE Amsterdam, The Netherlands \\ 2 Department of Psychology, Fordham University, New York, USA
}

\begin{abstract}
Early research on the mental health of civilians displaced by armed conflict focused primarily on the direct effects of exposure to war-related violence and loss. Largely overlooked in this war exposure model were the powerful effects of ongoing stressors related to the experience of displacement itself. An ecological model of refugee distress is proposed, drawing on research demonstrating that mental health among refugees and asylum seekers stems not only from prior war exposure, but also from a host of ongoing stressors in their social ecology, or displacement-related stressors. Implications of this model for addressing the mental health and psychosocial needs of refugees and other displaced populations are considered.
\end{abstract}

Received 18 January 2016; Accepted 8 March 2016; First published online 4 April 2016

Key words: Asylum seekers, daily stressors, ecological, mental health, refugees, trauma.

Recent estimates put the number of people displaced by organised violence at 60 million (UNHCR, 2015). This includes at least 32 million internally displaced people (IDPs), forced to abandon their homes and communities but still living within the borders of their home countries. Violence-related displacement is at a 20 year high, while the number of IDPs is at its highest level in 50 years. European governments and civil societies are actively, and at times contentiously, debating how to best respond to the dramatic increase in asylum seekers from protracted wars in Syria, Iraq and Afghanistan; meanwhile, the great majority of refugees from those and other conflicts seek shelter not in Europe but in neighbouring countries bordering their embattled homelands. [For the sake of ease, except where explicitly indicated, we use the term 'refugee' inclusively in this paper, to include anyone displaced by armed conflict.]

Paralleling this marked increase in forced migration has been a significant growth in research on the mental health of civilians displaced by armed conflict. Studies have examined diverse subgroups of displaced populations: children, adults, unaccompanied minors, torture survivors, IDPs, asylum seekers held in detention centres pending the outcome of their asylum claims, refugees resettled in high-income countries and the far greater number living in refugee camps or urban areas in low- and middle-income countries.

* Address for correspondence: K. E. Miller, War Child Holland, Helmholtzstraat 61, 1098 LE Amsterdam, The Netherlands.

(Email: kennethmiller@warchild.nl)
Several excellent reviews have synthesised the findings of this extensive literature (Lustig et al. 2004; Porter \& Haslam, 2005; Fazel et al. 2011; Siriwardhana et al. 2014; Tyrer \& Fazel, 2015), and all suggest that the mental health impact of armed conflict is compounded or alleviated by contexts of migration and resettlement. In other words, the mental health of refugees is powerfully influenced by war-related violence and loss combined with the conditions they encounter en route to and within their host countries.

Our aim in this paper is to highlight an empirically robust risk model that specifies the primary threats to mental health faced by survivors of conflict-driven displacement. The model includes pre-migration exposure to the violence and destruction of war, as well as a constellation of stressors related to the experience of displacement itself. Examples of 'post-migration' or displacement-related stressors that have been shown to influence mental health include social isolation resulting from the loss of social networks (Bennett \& Detzner, 1997; Silove et al. 1997; Priebe et al. 2013); unemployment due to a lack relevant work skills or to host-society restrictions on permission to work (Beiser et al. 1993; Silove, 1999; Priebe et al. 2013); poverty and a lack of access to basic resources (Pernice \& Brook, 1996; Rasmussen et al. 2010; Tay et al. 2015c); perceived discrimination (Ellis et al. 2008); increased family violence (Billings, 1996; Betancourt et al. 2012; Panter-Brick et al. 2014); a lack of safety in refugee camps (Rasmussen et al. 2010); and difficulties navigating settings of resettlement (Miller, 1999). For asylum seekers, stressors also include uncertainty regarding their legal status, the possibility of being deported to the country 
from which they fled, and for many, prolonged detention in asylum holding centres, while their asylum claims are adjudicated (Keller et al. 2003; Laban et al. 2004; Steel et al. 2004).

Post-migration stressors have consistently been found to predict levels of distress as powerfully as prior war exposure. In numerous studies, post-migration stressors have accounted for greater variance in levels of depression and anxiety than war-related experiences of trauma and loss (Sack et al. 1996; Miller et al. 2002a; Heptinstall et al. 2004; Ellis et al. 2008). They have also been positively associated with post-traumatic stress disorder (PTSD; Steel et al. 1999; Ellis et al. 2008; Betancourt et al. 2012). This is likely due to the traumatic nature of certain postmigration stressors (e.g., family violence), and to the depletion of refugees' coping resources by continuously stressful environmental conditions (e.g., poverty, unemployment, unsafe and overcrowded housing), which leaves them more vulnerable to the post-traumatic effects of prior war exposure (Steel et al. 1999; Nickerson et al. 2010; Rasmussen et al. 2010).

In the tradition of social ecological models (cf. Bronfenbrenner, 1977), in which factors at multiple levels (individual, family, community and society) influence human development, Miller \& Rasco (2004) proposed a social ecological framework for understanding the numerous stressors affecting the mental health of refugees. Within that framework, distress among refugees is understood as stemming not only from the violence and destruction of war, but also from stressful conditions linked to social and material conditions of everyday life following displacement. An ecological model of refugee distress includes risk factors at different points in time (pre-migration war exposure, perilous experiences of flight and current post-migration stressors) and at different levels of the social ecology. Moving from the individual level to the macrosystem, specific risk factors might include pre-existing psychological vulnerabilities and direct experiences of war-related violence traumatic stress; family conflict including interpersonal violence, and for children, impaired parenting due to parental trauma or depression; community tensions and limited resources within refugee camps; discrimination by host communities; and national policies that consign asylum seekers to periods of prolonged detention, or that limit opportunities for income generation and economic self-sufficiency. A social ecological model expands the view beyond the field's historical focus on war exposure and its adverse psychological effects, by drawing attention to current stressors associated with the challenges of adapting to life in exile, or displacement-related stressors. We believe that this broader view implies a set of mental health intervention strategies that extend well beyond the traditional clinical toolkit of psychotherapy and psychopharmacology.

In drawing attention to the influence of displacementrelated stressors on mental health it is not our intent to minimise the horrific and profoundly painful experiences many refugees endure before leaving their homelands. We have both worked clinically with refugees who escaped civil war and genocide, and have seen repeatedly the enduring effects that such violence can have on the mind and body. Nor is it our attention to overlook individual and group factors that have a bearing on psychosocial outcomes. A wealth of studies with displaced populations have found that risk and protective factors at the individual and group levels account for important variance in psychosocial distress (e.g., Sachs et al. 2008; Reed et al. 2012; Tol et al. 2013). Our point is simply that war exposure, for all of its destructive power, should not be assumed to be the sole, or even primary, source of distress among refugees.

\section{Early research with refugees based on the war exposure model}

Civil war, state terror and genocide in Southeast Asia and Latin America in the late 20th century gave rise to large-scale refugee movements to the USA and Canada, Australia and much of Western Europe. Refugees arrived sharing war stories replete with experiences of violence, terror and loss - experiences that met the trauma exposure criterion of the recently developed diagnosis of PTSD (American Psychiatric Association, 1980). Given their histories of exposure to traumatic stress, coupled with the mental health field's growing interest in psychological trauma, it was unsurprising that research with refugees quickly came to prioritise the assessment of PTSD. PTSD prevalence rates among refugees have varied markedly across studies, with estimates ranging from below 5\% to over 90\% (Fazel et al. 2005, 2011; Porter \& Haslam, 2005; Porterfield et al. 2010). Similarly wide variability has been found for depression, anxiety and psychosocial impairment. This variability reflects numerous factors, including differences in severity of war exposure and in settings of displacement (e.g., refugee camps adjacent to ongoing violence versus resettlement in high-income countries), as well as methodological variability (e.g., self-report versus clinical interview, community versus clinical samples and variation in the quality of cross-cultural instrument adaptation). Larger and more rigorous studies have generally found lower rates of distress; however, even meta-analytic studies have yielded conflicting results (Fazel et al. 2005; Porter \& Haslam, 2005). Overall, the available data suggest that refugees have 
higher levels of PTSD and other common mental disorders than those found in the populations of their host societies, and higher symptom levels than war-affected civilians who have not been displaced. Although there is a paucity of longitudinal data regarding the persistence of distress and clinical disorder among refugees, several studies have found that symptom levels remained elevated even several years post-migration (Kinzie et al. 1986, 1989; McSharry \& Kinney, 1992; Sack et al. 1993; Steel et al. 2002).

Although it was clear from early studies that many refugees were at risk of significant and potentially enduring distress, the causes of that distress were less well established. It was often assumed that high symptoms levels were the result of pre-migration experiences of war-related violence and loss - a war exposure model of distress and psychopathology. Other researchers sought to test this assumption by examining the relationship between severity of war exposure and level of symptomatology or the likelihood of receiving a clinical diagnosis. Findings generally supported a 'dose response effect', with higher levels of war exposure predicting greater distress or a higher probability of diagnosis (Mollica et al. 1998; Steel et al. 2009). However, the strength of the effect varied considerably, and models using war exposure as the sole or primary predictor of mental health status typically left a great deal of variance in symptom levels unexplained (Silove, 1999; Miller \& Rasmussen, 2010a, b).

Little was known about the psychological impact of displacement and the numerous stressors it entails, because post-migration stressors generally were not part of the models being tested. The salience of trauma and loss in refugees' war stories led the field to overlook the stressful nature of life in exile. However, as researchers and clinicians began to ask about the challenges faced by refugees after becoming displaced, the salience of postmigration stressors became increasingly apparent. Alongside stories of trauma and loss, refugees described numerous stressors in their day-to-day lives related to the experience of displacement (Hitchcox, 1990; Billings, 1996; Miller et al. 2002b). With the addition of postmigration stressors such as social isolation, poverty, family violence, discrimination and uncertainty regarding asylum status, predictive models were increasingly able to account for a great deal of previously unaccounted for variance in symptoms levels (Pernice \& Brook, 1996; Sack et al. 1996; Gorst-Unsworth \& Goldenberg, 1998; Michultka et al. 1998; Miller et al. 2002a; Ellis et al. 2008). The ecological model of refugee distress showed significantly greater predictive power than the more narrowly focused war exposure model that had guided earlier research.

Although the direct effect of war exposure on mental health, and PTSD in particular, generally remained significant after post-migration stressors were added to models, the strength of that effect was consistently diminished. This suggested that post-migration stressors partially mediate the impact of war trauma on psychological wellbeing (Steel et al. 1999; Nickerson et al. 2010; Rasmussen et al. 2010; Jordans et al. 2012). This mediating role is consistent with what we found in our review of war exposure and daily stressors among civilians living in settings of armed conflict (Miller \& Rasmussen, 2010a, b). We defined daily stressors as the stressful events and conditions of daily life that are caused or exacerbated by organised violence. Daily stressors threaten mental health by contributing to high levels of stress and depleting coping resources, and research has consistently linked them to numerous adverse psychosocial outcomes (for a brief review, see Miller \& Rasmussen, 2014). There is clearly a great deal of overlap between stressors associated with forced displacement and daily stressors related to armed conflict. Conceptually, we find it useful to view displacement-related stressors as a specific constellation of daily stressors that stem from (or are made worse by) the combined experiences of armed conflict and forced migration (See Fig. 1). In other words, displacement-related stressors area subset of daily stressors that should be attended to in humanitarian aid work.

\section{Displacement-related stressors as targets of refugee interventions}

Interventions aimed at improving the mental health of refugees have generally been focused on the treatment of PTSD and depression assumed to stem primarily from war exposure. Much of the intervention literature has focused on the efficacy of trauma-treatment protocols (e.g., Narrative Exposure Therapy or NET; Neuner et al. 2004), Eye Movement Desensitisation Retraining (ter Heide et al. 2011) and various cognitivebehavioural methods (e.g., Hinton et al. 2012), as well as the use of psychiatric medications to manage symptoms of trauma, depression and anxiety (Smajkic et al. 2001). Treatment effects have been highly variable, ranging from none to small in a meta-analysis of trauma treatments for survivors of torture (Patel et al. 2014), to medium and large in treatment studies of refugees not selected based on torture history (Murray et al. 2010; Lambert \& Alhassoon, 2014).

Several intervention researchers in high-income countries have suggested that the failure to address displacement-related stressors such as poverty, unemployment, social isolation and housing difficulties may limit the effectiveness of psychotherapy and psychopharmacology with refugee clients (Kinzie \& Fleck, 


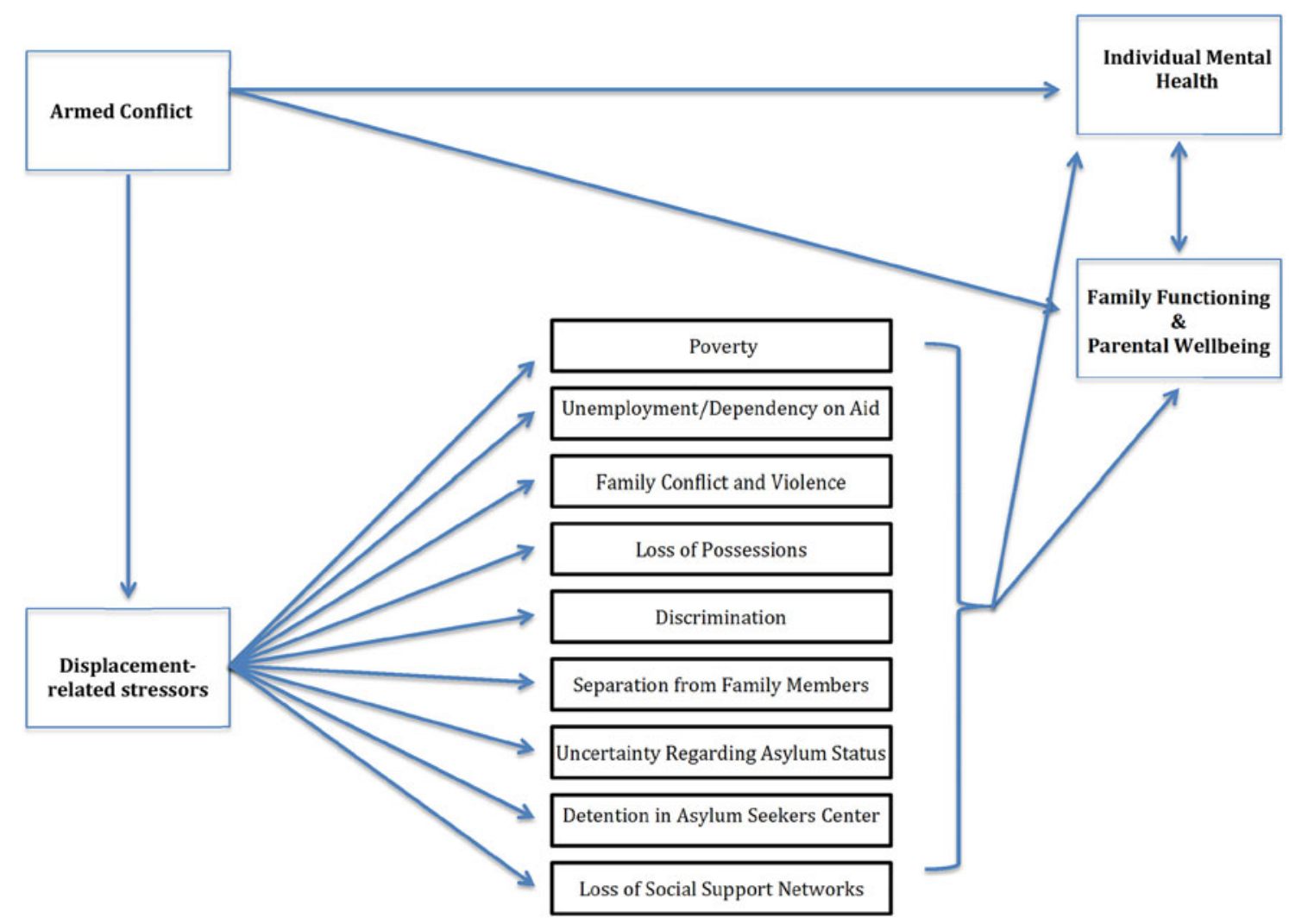

Fig. 1. Armed conflict, displacement and mental health.

1987; Pejovic et al., 1997; Miller, 1999; Goodkind et al. 2013). Growing recognition of the adverse psychological impact of post-migration stressors has led to a multiservice approach in many clinical settings, in which services such as individual and group therapy and psychiatric medication are complemented with case management aimed at helping refugee clients address the social and material conditions of their daily lives. In addition to providing assistance with housing, health, education and employment issues, such services might also include connecting refugees with each other and with sympathetic non-refugees to foster community support (e.g., Goodkind, 2006). These more comprehensive approaches address the impact of prior war exposure as well as ongoing stressors, and appear to hold considerable potential for refugees who have access to clinicbased mental health services.

Unfortunately, health centres offering psychological care are not available for the majority of the world's displaced people. An increasingly popular response to this scarcity of mental health services has been the development of so-called 'task-shifting' methods in which trained paraprofessionals implement grouplevel therapeutic interventions in refugee communities. This approach has shown promise in reducing symptoms of distress and improving psychosocial wellbeing in efficacy trials conducted with refugees in several low- and middle-income countries (Bolton et al. 2007; Ager et al. 2011; Murray et al. 2014). Because efficacy trials are often well-funded and highly resourced, a critical next step will be effectiveness studies to assess the impact of task sharing models under the normal, lower-resourced conditions in which many nongovernmental organisations (NGOs) and local health centres operate.

Although task-shifting interventions with conflictaffected populations have typically focused on ameliorating the post-traumatic effects of war exposure, recent studies have also demonstrated their potential for targeting daily or post-migration stressors. For example, task-shifting approaches have been used successfully to reduce both child abuse and intimate partner violence in post-conflict societies and displaced communities (Hossain et al. 2014; Sim, 2014; Sim et al. 2014; DeVries et al. 2015).

\section{A broader approach to improving refugees' mental health}

An important implication of research on the impacts of displacement-related stressors is that it should be 
possible to improve the mental health of refugees through interventions that are not formally conceived of as psychotherapeutic in nature. Projects aimed at fostering livelihoods, changing policies to permit refugee employment, reducing family violence, minimising the duration of asylum application processes, and creating settings where people can find new sources of social support may not be designed to improve mental health, yet may do so collaterally. We briefly consider evidence that lends provisional support to this idea, as well findings suggesting a somewhat more complex picture. Although the findings discussed below are drawn largely from studies of refugees in high-income countries, we believe they are germane to displaced populations in low- and middle-income settings as well.

Legal procedures facing asylum seekers often make the experience of displacement markedly more stressful. Several studies have shown that asylum seekers with longer stays in detention centres have worse mental health (Keller et al. 2003; Robjant et al. 2009). Keller et al. (2003) further found that symptoms of distress dropped significantly among asylum seekers following their release from detention. In a similar vein, a study by Nickerson et al. (2010) of non-detained Mandean asylum seekers in Australia found a significant improvement in mental health when their legal status was changed from temporary (asylum seeking) to permanent (refugee). This result was further supported by findings from research in the USA that receiving asylum had by far the largest effect size reducing symptom severity among a sample of asylum seekers, even after controlling for engagement in psychotherapy and social services (Raghavan et al. 2013). Taken together, these studies suggest the psychological benefits of individuallevel interventions that aid in reducing or avoiding detention, and legal advocacy to facilitate the speedy processing of asylum claims. Higher levels of intervention would include political advocacy for: (1) eliminating the unnecessary use of detention centres, (2) minimising the duration of detention when deemed necessary, and (3) advocating for simpler and more efficient asylum application processes.

The degradation of social networks through warrelated death and displacement is pervasive among refugees, and increases the risk of social isolation, depression, and serious physical health problems (Silove et al. 1997; Chesney \& Darbes, 1998; Priebe et al. 2013). Community interventions designed to foster new social support networks among refugees are common, but their psychological benefits have seldom been rigorously studied. An exception is the work of Goodkind, who used 'learning circles' to facilitate cultural and social support (Goodkind, 2006; Goodkind et al. 2013). In a recent study of women refugees from the Great Lakes region of Africa living in the USA, Goodkind and her colleagues found that postintervention levels of psychological distress were significantly reduced and quality of life was improved, with both outcomes specifically related to increased social support from the intervention (Goodkind et al. 2013). Whether there are certain conditions that influence the likelihood of social settings being perceived as supportive is an important question. It may be, for example, that for some highly traumatised individuals, social gatherings where news and stories from the homeland are shared may trigger heightened anxiety and reminders of traumatic experiences. In such cases, a certain amount of healing, either individually or in therapeutic groups, may be a prerequisite to benefitting from the positive effects of social engagement.

As noted earlier, the adverse effects of unemployment and poverty on the psychosocial wellbeing of refugees have been well documented (Silove 1999; Beiser et al. 1993; Priebe et al. 2013). More broadly, enduring poverty and unemployment contribute to the social marginalisation of refugees within their host societies (Duke et al. 1999; Ager \& Strang, 2008). Refugees are restricted from legal employment in many countries, consigning them to exploitative black market labour and dependence on government or humanitarian aid. Where employment is allowed, many refugees lack the relevant skill sets to find work in their new environment. Policy changes that permit legal employment, as well as livelihoods programmes that provide vocational skills training and access to work opportunities, hold promise as strategies not only for reducing dependence on aid among refugees, but also improving their mental health. Unfortunately, in our review for this paper we found no studies directly addressing the psychological effects of interventions aimed at helping refugees become gainfully employed.

Several studies have examined the mental health impact of various types of poverty reduction interventions in non-refugee populations in low- and middle-income countries. Research has yielded mixed results to date. Cash transfer programs to poor families have showed significant mental health benefits for adolescent girls in Malawi (Baird et al. 2011), and have significantly reduced children's behaviour problems in Mexico (Fernald et al. 2009). In contrast, microfinance (microcredit) programs have generally yielded disappointing results. Microcredit - loans based on little or no collateral - initially seemed like a promising strategy for families living in poverty, including refugees, without adequate capital to start income generation ventures. However, microfinance programmes have generally failed to lift poor families out of poverty or reduce poverty-related stressors, and they have not 
shown positive effects on the mental health of programme recipients (Ahmed et al. 2001; Ozer et al. 2009; Stark et al. 2014). To our knowledge, evaluations of microcredit programmes specifically with refugees have not been published.

We recognise that addressing issues of poverty and unemployment in displaced populations is complex in ways that go beyond quality of programme design and implementation. Providing access to employment for refugees for refugees occurs in contexts that are highly political, and may evoke fear and resentment if refugees are perceived as competing for scarce jobs in countries with tight labour markets.

We also realise that some individuals, struggling with the disabling effects of severe war-related trauma and depression may need psychological assistance before they are able to take advantage of livelihoods programmes and employment opportunities. This underscores the mutually influential relationship between the effects of war exposure and post-migration stressors. For refugees severely affected by pre-migration experiences of trauma, some degree of healing may be necessary before they are able to make use of resources in the post-migration environment; conversely, reducing the stressful nature of life in exile may lessen the intensity of war-related trauma and facilitate a natural process of psychological healing.

\section{Why are displacement-related stressors so strongly linked to mental health?}

It may seem counterintuitive that displacement-related stressors are as powerfully related to mental health as the terrible experiences of violence and loss that lead people to become displaced. In 2010, we posited four factors that might account for the strong relationship between daily stressors and mental health in conflict-affected societies (Miller \& Rasmussen, $2010 a, b)$. Given that displacement-related stressors are in fact a subset of daily stressors, we briefly summarise each of the four explanatory factors here.

The first factor is temporal proximity. Daily stressors represent immediate and ongoing sources of stress, whereas war exposure may be a more distal experience, particularly in post-conflict settings and among refugees who have been displaced for extended periods of time. Natural processes of psychological recovery may have ameliorated the mental health impact of war-related trauma and loss, while daily, or displacement-related, stressors continue to tax coping resources and threaten psychological wellbeing.

Second, daily stressors 'represent noxious stimuli that are largely beyond people's control' (Miller \& Rasmussen, 2010a, b: 13). Research on both animals and humans has consistently shown that a lack of control over aversive stimuli is causally related to a host of adverse psychological and physical outcomes, particularly when exposure is prolonged or unpredictable (Sapolsky, 2004). Displacement-related stressors such as discrimination, detention, uncertainty regarding asylum status and a lack of access to basic resources all represent continuous stressors over which refugees have limited or no control. Moreover, although conflict-related displacement ideally entails a move away from danger towards greater safety, journeys into exile are often fraught with peril, and safety concerns within refugee camps and settlements are frequently paramount (Rasmussen et al. 2010; Bartels \& Hamill, 2014). Even in high-income countries, refugees may end up living in neighbourhoods with high crime rates, and feel threatened by hostility from members of the host society. It seems reasonable to hypothesise that the continuous perception of threat and associated heightened levels of distress contribute to the association between displacement-related stressors and mental health status.

Third, daily stressors are pervasive within waraffected populations, while the degree of direct exposure to the violence of war is often highly variable (Macksoud \& Aber, 1996). Similarly, severity of war exposure within refugee communities varies markedly, while nearly all refugees contend with a range of displacement-related stressors. To illustrate, in 1982 many indigenous Guatemalans fled north into Mexico immediately upon learning of army massacres in neighbouring villages. Consequently, while some of the refugees witnessed horrific violence and many lost loved ones in the military's counterinsurgency campaign, others escaped before the violence reached their communities. In contrast, nearly all of the refugees in the camps of Southern Mexico confronted the daily challenges of poverty, inadequate housing, lack of access to land for growing food, exploitative wage labour, separation from loved ones, repeated displacement to new camps, fear of cross-border incursions by Guatemalan soldiers, and a lack of access to adequate nutrition and healthcare (Manz, 1988; Billings, 1996; Miller, 1996).

Finally, the term 'daily stressors' includes a diverse set of stressful phenomena, from lower-intensity chronic stressors such as inadequate housing, unemployment and social isolation, to acute and potentially traumatic experiences such as child abuse and intimate partner violence. Displacement-related stressors likewise include an array of stressful conditions and experiences, from low-intensity stressors to patently traumatic events. This suggests at least two pathways by which they may increase the risk for psychiatric disorders, including PTSD: first, through exposure to potentially traumatic stressors such as 
family and community violence, and second, by overwhelming individual and family coping resources through exposure to the less intense but continuously stressful challenges of life in exile.

\section{Conclusion}

A social ecological model of refugee distress illustrates a simple but powerful point: distress within displaced populations is as likely to be related to ongoing stressors in their social ecology as it is to prior war exposure. This reality underscores the importance of thoroughly assessing current environmental stressors as well as history of exposure to conflict-related violence and loss, when seeking to understand and address the mental health needs of refugee communities. Inadequate assessment of post-migration stressors risks the misattribution of distress to prior war exposure, when it may be due partly or wholly to ongoing stressors that could readily be targeted for change. Miller et al. (2006) give the example of a Bosnian refugee whose severe PTSD and depression turned out to primarily the result of extreme and ongoing domestic violence, a fact that only emerged several months into her treatment for what was assumed to war trauma. How we respond to psychological difficulties depends on our understanding of their root causes. Effective responses will likely differ for depression that stems from unresolved grief, versus depression resulting from unemployment, poverty, family violence, or the loss of agency stemming from restrictions on freedom of movement beyond the confines of refugee camps. There has been some research modelling sources of distress in displaced populations in a more holistic manner. Perhaps the most prominent is Silove and colleagues' model of Adaptation and Development after Persecution and Trauma, or the ADAPT model. Among refugees from West Papua living in Papua New Guinea the ADAPT dimensions insecurity, disrupted bonds and networks, access to justice, identity disruptions, transitioning to new roles and identities had effects on PTSD beyond war trauma (Silove, 2014; Tay et al. 2015a, b). These ADPAT domains correspond conceptually to several categories of displacement-related stressors within a social ecological model of refugee distress. Unfortunately, there remains a critical gap in the literature on the mental health benefits of interventions that target stressors such as these.

There has been considerable debate regarding the relative merits of treating the enduring effects of war trauma versus targeting the stressful conditions that war and displacement have on mental health through their impact on the social ecology of everyday life (Miller \& Rasmussen, 2010a, b; Neuner, 2010). The available data strongly suggest that (1) both war trauma and post-migration stressors exert a powerful influence on mental health, and (2) the post-migration environment plays a critical role in either fostering or impeding recovery from war-related trauma and grief. An ecological model offers a framework for understanding the diversity of factors affecting the psychological wellbeing of refugees, and for responding in ways that correspond to the various sources of their distress.

\section{Acknowledgement}

The authors wish to acknowledge the helpful feedback from the reviewers on an earlier version of this article.

\section{Financial Support}

This research received no specific grant from any funding agency, commercial or not-for-profit sectors.

\section{Conflict of Interest}

None.

\section{References}

Ager A, Strang A (2008). Understanding integration: a conceptual framework. Journal of Refugee Studies 21, 166-191. doi: 10.1093/jrs/fen016

Ager A, Akesson B, Stark L, Flouri E, Okot B, McCollister F, Boothby N (2011). The impact of the school-based Psychosocial Structured Activities (PSSA) program on conflict-affected children in northern Uganda. Journal of Child Psychology and Psychiatry 52, 1124-1133. doi: 10.1111/ j.1469-7610.2011.02407.x

Ahmed SM, Choudhury M, Bhuiya A (2001). Micro-credit and emotional well-being: experience of poor rural women from Matlab, Bangladesh. World Development 29, 1957-1966.

American Psychiatric Association (1980). Diagnostic and Statistical Manual, 3rd edn, Revised. American Psychiatric Association: Washington, DC.

Baird S, de Hoop J, Özler B (2011). Income shocks and adolescent mental health. Journal of Human Resources 48, 370-403.

Bartels S, Hamill K (2014). Running Out of Time: Survival of Syrian Refugee Children in Lebanon. FXB Center for Health and Human Rights at Harvard University: Cambridge, MA. Retrieved from http://cdn2.sph.harvard.edu/wpcontent/uploads/sites/5/2014/01/FXB-Center-SyrianRefugees-in-Lebanon_Released-01-13-14.pdf

Beiser M, Johnson P, Turner J (1993). Unemployment, underemployment and depressive affect among Southeast Asian refugees. Psychological Medicine 23, 731-743.

Bennett J, Detzner D (1997). Loneliness in cultural context: a look at the life-history narratives of older Southeast Asian 
refugee women. In The Narrative Study of Lives (ed. A Lieblich and J Ruthellen), pp. 113-146. Sage Publications, Inc: Thousand Oaks, CA.

Betancourt TS, Newnham EA, Layne CM, Kim S, Steinberg AM, Ellis H, Birman D (2012). trauma history and psychopathology in war-affected refugee children referred for trauma-related mental health services in the United States. Journal of Traumatic Stress 25, 682-690.

Billings D (1996). Identities, consciousness, and organizing in exile: Guatemalan refugee women in the camps of southern Mexico. Ph.D. diss., University of Michigan.

Bolton P, Bass J, Betancourt T, Speelman L, Onyango G, Clougherty K, Verdeli H (2007). Interventions for depression symptoms among adolescent survivors of war and displacement in Northern Uganda: a randomized controlled trial. JAMA 298, 519-527.

Bronfenbrenner $\mathbf{U}$ (1977). Towards an experimental ecology of human development. American Psychologist 32.

Chesney M, Darbes L (1998). Social support and heart disease in women: implications for intervention. In Women, Stress, and Heart Disease (ed. K Orth-Gomer and M Chesney), pp. 165-182. Lawrence Erlbaum Associates, Inc., Publishers: Mahwah, NJ.

DeVries KM, Knight L, Child JC, Mirembe A, Nakuti J, Jones R, Naker D (2015). The Good School Toolkit for reducing physical violence from school staff to primary school students: a cluster-randomized controlled trial in Uganda. Lancet Global Health 3, 378-386. doi: http://dx.doi. org/10.1016/S2214-109X(15)00060-1.

Duke K, Sales R, Gregory J (1999). Refugee resettlement in Europe. In Refugees, Citizenship and Social Policy in Europe (ed. A Bloch and C Levy), pp. 105-127. Palgrave Macmillan: Basingstoke.

Ellis H, MacDonald H, Lincoln A, Cabral H (2008). Mental health of Somali adolescent refugees: the role of trauma, stress, and perceived discrimination. Journal of Consulting and Clinical Psychology 76, 184-193.

Fazel M, Wheeler J, Danesh J (2005). Prevalence of serious mental disorder in 7000 refugees resettled in western countries: a systematic review. Lancet 365, 1309-1314.

Fazel M, Reed RV, Panter-Brick C, Stein A (2011). Mental health of displaced and refugee children resettled in high-income countries: risk and protective factors. Lancet 379, 266-282. doi: 10.1016/S0140-6736(11)60051-2

Fernald L, Gertler P, Neufeld LM (2009). 10-year effect of Oportunidades, Mexico's conditional cash transfer programme, on child growth, cognition, language, and behaviour: a longitudinal follow-up study. Lancet 374, 1-9. doi: 10.1016/S0140-6736(09)61676-7.

Goodkind J (2006). Promoting Hmong refugees' well-being through mutual learning: valuing knowledge, culture, and experience. American Journal of Community Psychology 37, 77-93.

Goodkind JR, Hess JM, Isakson B, LaNoue M, Githinji A, Roche N, Parker DP (2013). Reducing refugee mental health disparities: a community-based intervention to address postmigration stressors with African adults. Psychological Services, 1-14. Advance online publication. doi: 10.1037/a0035081.
Gorst-Unsworth C, Goldenberg E (1998). Psychological sequelae of torture and organized violence suffered by refugees from Iraq: trauma-related factors compared with social factors in exile. British Journal of Psychiatry 172, 90-94.

Heptinstall E, Sethna V, Taylor E (2004). PTSD and depression in refugee children: associations with pre-migration trauma and post-migration stress. European Journal of Child and Adolescent Psychiatry 13, 373-380.

Hinton D, Rivera EI, Hofmann SG, Barlow DH, Otto MW (2012). Adapting CBT for traumatized refugees and ethnic minority patients: examples from culturally adapted CBT (CA-CBT). Transcultural Psychiatry 49, 340-365. doi: 10.1177/1363461512441595.

Hitchcox L (1990). Vietnamese Refugees in Southeast Asian Camps. Macmillan Academic and Professional Limited: Hampshire, England.

Hossain M, Zimmerman C, Kiss L, Abramsky T, Kone D, Bakayoka-Topolska M, Watts C (2014). Working with men to prevent intimate partner violence in a conflict-affected setting: a pilot cluster randomized controlled trial in rural Côte d'Ivoire. BMC Public Health 14, 1-13. Retrieved from http://www.biomedcentral.com/14712458/14/339

Jordans MJD, Semrau M, Thornicroft G, van Ommeren M (2012). Role of current and perceived needs in explaining the association between past trauma exposure and distress in humanitarian settings in Jordan and Nepal. British Journal of Psychiatry 201, 276-281.

Keller AS, Rosenfeld B, Trinh-Shevrin C, Meserve C, Sachs E, Leviss J, Ford D (2003). Mental health of detained asylum seekers. Lancet 362, 1721-1723. doi: 10.1016/ S0140-6736(03)14846-5

Kinzie JD, Fleck J (1987). Psychotherapy with severely traumatized refugees. American Journal of Psychotherapy 41, 82-94.

Kinzie JD, Sack W, Angell R, Manson S, Rath B (1986). The psychiatric effects of massive trauma on Cambodian children: I. The children. Journal of the American Academy of Child and Adolescent Psychiatry 25, 370-376.

Kinzie JD, Sack W, Angell R, Clarke G, Ben R (1989). A three-year follow-up of Cambodian young people traumatized as children. American Academy of Child and Adolescent Psychiatry 28, 501-504.

Laban CJ, Gernaat HB, Komproe IH, Schreuders BA, de Jong JT (2004). Impact of a long asylum procedure on the prevalence of psychiatric disorders in the Iraqi asylum seekers in the Netherlands. Journal of Nervous and Mental Disease 192, 843-851.

Lambert J, Alhassoon O (2014). Trauma-focused therapy for refugees: meta-analytic findings. Journal of Counseling Psychology 62, 28-37.

Lustig SL, Kia-Keating M, Knight WG, Geltman P, Ellis H, Kinzie JD, Saxe G (2004). Review of child and adolescent refugee mental health. Journal of the American Academy of Child and Adolescent Psychiatry 43, 24-36. doi: 10.1097/ 00004583-200401000-00012

Macksoud MS, Aber JL (1996). The war experience and psychosocial development of children in Lebanon. Child Development 67, 70-88. 
Manz B (1988). Refugees of a Hidden War. SUNY Press: New York.

McSharry S, Kinney R (1992). Prevalence of psychiatric disorders in Cambodian refugees: a community random sample. Unpublished manuscript, Social Research Institute, Graduate School of Social Work, University of Utah, Salt Lake City, Utah.

Michultka D, Blanchard E, Kalous T (1998). Responses to civilian war experiences: predictors of psychological functioning and coping. Journal of Traumatic Stress 11, 571-577.

Miller KE (1996). The effects of state terrorism and exile on indigenous Guatemalan refugee children: a mental health assessment and an analysis of children's narratives. Child Development 67, 89-106.

Miller KE (1999). Rethinking a familiar model: psychotherapy and the mental health of refugees. Journal of Contemporary Psychotherapy 29, 283-306.

Miller KE, Rasco LM (2004). An ecological framework for addressing the mental health needs of refugee communities. In The Mental Health of Refugees: Ecological Approaches to Healing and Adaptation (ed. KE Miller and LM Rasco), pp. 1-64. Lawrence Erlbaum Associates, Inc: Mah Wah, NJ.

Miller KE, Rasmussen A (2010a). War exposure, daily stressors, and mental health in conflict and post-conflict settings: bridging the divide between trauma-focused and psychosocial frameworks. Social Science and Medicine 70, 7-16.

Miller KE, Rasmussen A (2010b). Mental health and armed conflict: the importance of distinguishing between war exposure and other sources of adversity: a response to Neuner. Social Science and Medicine 1781, 1385-1389.

Miller KE, Rasmussen A (2014). War experiences, daily stressors, and mental health five years on: elaborations and future directions. Intervention 12, 33-42.

Miller KE, Weine S, Ramic A, Brkic N, Djuric Bjedic Z, Smajkic A, Boskailo E (2002a). The relative contribution of war experiences and exile-related stressors to levels of psychological distress among Bosnian refugees. Journal of Traumatic Stress 15, 377-387.

Miller KE, Worthington G, Muzurovic J, Tipping S, Goldman A (2002b). Bosnian refugees and the stressors of exile: a narrative study. American Journal of Orthopsychiatry 72, 341-354.

Miller KE, Kulkarni M, Kushner H (2006). Beyond trauma-focused psychiatric epidemiology: bridging research and practice with war-affected populations. American Journal of Orthopsychiatry 76, 409-422.

Mollica R, McInnes K, Pham T, Fawzi M, Smith C, Murphy E, Lin L (1998). The dose-effect relationships between torture and psychiatric symptoms in Vietnamese ex-political detainees and a comparison group. Journal of Nervous and Mental Disease 186, 543-553.

Murray K, Davidson GR, Schweitzer RD (2010). Review of refugee mental health interventions following resettlement: best practices and recommendations. American Journal of Orthopsychiatry 80, 576-585. doi: 10.1111/ j.1939-0025.2010.01062.x

Murray L, Dorsey S, Haroz E, Lee C, Alsiary M, Haydary A, Bolton P (2014). A common elements treatment approach for adult mental health problems in low- and middleincome countries. Cognitive and Behavioral Practice 21, 11-123.

Neuner F (2010). Assisting war-torn populations: should we prioritize reducing daily stressors to improve mental health? Comment on Miller and Rasmussen. Social Science and Medicine 71, 1381-1384.

Neuner F, Schauer M, Klaschik C, Karunakara U, Elbert T (2004). A comparison of narrative exposure therapy, supportive counseling, and psychoeducation for treating posttraumatic stress disorder in an African refugee settlement. Journal of Consulting and Clinical Psychology 72, 579-587.

Nickerson A, Steel Z, Bryant R, Brooks R, Silove D (2010). Change in visa status amongst Mandean refugees: relationship to symptoms and living difficulties. Psychiatry Research 187, 267-274.

Ozer EJ, Fernald LCH, Manley J, Gertler P (2009). Effects of a conditional cash transfer program on children's behavior problems. Pediatrics 123, e630-e637. doi: 10.1542/peds.20082882.

Panter-Brick C, Grimon M, Eggerman M (2014). Caregiverchild mental health: a prospective study in conflict and refugee settings. Journal of Child Psychology and Psychiatry 55, 313-327.

Patel N, Kellezi BWilliams AC (2014). Psychological, social and welfare interventions for psychological health and well-being of torture survivors. Cochrane Database of Systematic Reviews 11, 1-66. doi: 10.1002/14651858. CD009317.pub2.

Pejovic M, Jovanovic A, Djuric S (1997). Psychotherapy experience with patients treated for war psychotraumas. Psychiatriki 8, 136-141.

Pernice R, Brook J (1996). Refugees' and immigrants' mental health: association of demographic and post-migration factors. Journal of Social Psychology 136, 511-519.

Porter M, Haslam N (2005). Predisplacement and postdisplacement factors associated with mental health of refugees and internally displaced persons: a meta-analysis. JAMA 294, 602-612.

Porterfield K, Akinsulure-Smith A, Benson M, Betancourt T, Ellis BH, Kia-Keating M, Miller KE (2010). Resilience and Recovery after War: Refugee Children in the United States. American Psychological Association: Washington, DC.

Priebe S, Gavrilovic JJ, Bremner S, Adjudovic D, Franciscovic T, Galeazzi GM, Bogic M (2013). Psychological symptoms as long-term consequences of war experiences. Psychopathology 46, 45-64. doi: 10.1159/ 000338640.

Raghavan S, Rasmussen A, Rosenfeld B, Keller AS (2013). Correlates of symptom reduction in treatment-seeking survivors of torture. Psychological Trauma: Theory, Research, Practice, and Policy 5, 377-383. doi: 10.1037/ a0028118

Rasmussen A, Nguyen L, Wilkinson J, Vundla S, Raghavan S, Miller KE, Keller A (2010). Rates and impact of trauma and current stressors among Darfuri refugees in Eastern Chad. American Journal of Orthopsychiatry 80, 227-236. doi: 10.1111/j.1939-0025.2010.01026.x 
Reed RV, Fazel M, Jones L, Panter-Brick C, Stein A (2012). Mental health of displaced and refugee children resettled in middle- and low-income countries: risk and protective factors. Lancet 379, 250-265.

Robjant K, Hassan R, Catona C (2009). Mental health implications of detaining asylum seekers: systematic review. British Journal of Psychiatry 194, 306-312.

Sachs E, Rosenfeld R, Lhewa D, Rasmussen A, Keller A (2008). Entering exile: trauma, mental health and coping among Tibetan refugees arriving in Dharamsala, India. Journal of Traumatic Stress 21, 199-208.

Sack WH, Clarke G, Him C, Dickason D, Goff BLK, Kinzie JD (1993). A 6-year follow-up study of Cambodian refugee adolescents traumatized as children. Journal of the American Academy of Child Psychiatry 32, 431-437.

Sack WH, Clarke GN, Seeley J (1996). Multiple forms of stress in Cambodian adolescent refugees. Child Development 67, 107-116. doi: 10.1111/j.1467-8624.1996.tb01722.x

Sapolsky R (2004). Why Zebras Don't Get Ulcers. Owl Books: New York.

Silove D (1999). The psychosocial effects of torture, mass human rights violations, and refugee trauma. Journal of Nervous and Mental Disease 187, 200-207.

Silove D (2014). The ADAPT model: a conceptual framework for mental health and psychosocial programming in psychosocial settings. Intervention 11, 237-248.

Silove D, Sinnerbrink I, Field A, Manicavasagar V, Steel Z (1997). Anxiety, depression and PTSD in asylum-seekers: associations with pre-migration trauma and post-migration stressors. British Journal of Psychiatry 170, 351-357. doi: 10.1192/bjp.170.4.351.

Sim A (2014). Building Happy Families. International Rescue Committee: New York. Retrieved from http://www.rescue. org/sites/default/files/resource-file/HappyFamilies_report_ FINAL_18Nov14.pdf

Sim A, Puffer E, Green E, Chase R, Zayzay J, Garcia-Rolland E, Boone L (2014). Parents Make the Difference: Findings from a Randomized Impact Evaluation of a Parenting Program in Rural Liberia. International Rescue Committee: New York.

Siriwardhana C, Ali SS, Roberts B, Stewart R (2014). A systematic review of resilience and mental health outcomes of conflict-driven adult forced migrants. Conflict and Health 8, 1-14. Retrieved from http://www.conflictandhealth.com/ content/8/1/13.

Smajkic A, Weine S, Durić-Bijedić Z, Boskaio E, Lewis J, Pavković I (2001). Sertraline, paroxetine, and venlafaxine in refugee posttraumatic stress disorder with depression symptoms. Journal of Traumatic Stress 14, 445-452.

Stark L, Kassim M, Sparling T, Buscher D, Yu G, Boothby N (2014). Assessing the impact of microfinance programming on children: an evaluation from post-tsunami Aceh. Disasters, 1-21. doi: 10.1111/disa.12101.
Steele Z, Silove D, Bird K, McGorry P, Mohan P (1999). Pathways from war trauma to posttraumatic stress symptoms among Tamil asylum seekers, refugees, and immigrants. Journal of Trauma Stress 12, 421-435.

Steel Z, Silove D, Phan T, Bauman A (2002). Long-term effect of psychological trauma on the mental health of Vietnamese refugees resettled in Australia: a population-based study. Lancet 360, 1056-1062.

Steel Z, Momartin S, Bateman C, Hafshejani A, Silove D, Everson N, Roy K, Mares Snk (2004). Psychiatric status of asylum seeker families held for a protracted period in a remote detention centre in Australia. Australian and New Zealand Journal of Public Health 28, 527-536.

Steel Z, Chey T, Silove D, Marnane C, Bryant RA, van Ommeren M (2009). Association of torture and other potentially traumatic events with mental health outcomes with populations exposed to mass conflict and displacement: a systematic review and meta-analysis. JAMA 32, 537-549.

Tay AK, Rees S, Chen J, Kareth M, Silove D (2015a). Examining the broader effects of mass conflict on PTSD symptoms and functional impairment amongst West Papuan refugees resettled in Papua New Guinea (PNG). Social Science and Medicine 132, 72-78.

Tay AK, Rees S, Chen J, Kareth M, Silove D (2015b). Corrigendum to 'Examining the broader effects of mass conflict on PTSD symptoms and functional impairment amongst West Papuan refugees resettled in Papua New Guinea (PNG).' Social Science and Medicine 138, 13.

Tay AK, Rees S, Chen J, Kareth M, Lahe S, Kitau R, Silove D (2015c). Associations of conflict-related trauma and ongoing stressors with the mental health and functioning of west Papuan refugees in port Moresby, Papua New Guinea (PNG). PLOS ONE 10, 1-19. doi: 10.1371/journal.pone.0125178.

ter Heide FJJ, Mooren TM, Kleijn WM, de Jongh A, Kleber RJ (2011). EMDR versus stabilization in asylum seekers and refugees: results of a pilot study. European Journal of Psychotraumatology 2, 2-11. doi: 10.3402/ejpt.v2i0.5881.

Tol WA, Song S, Jordans MJD (2013). Annual research review: resilience and mental health in children and adolescents living in areas of armed conflict - a systematic review of findings in low- and middle-income countries. Journal of Child Psychology and Psychiatry 54, 445-460.

Tol WA, Barbui C, Bisson J, Cohen J, Zeinab H, Jones L, van Ommeren M (2014). World Health Organization guidelines for management of acute stress, PTSD, and bereavement: key challenges on the road ahead. PLoS Medicine 11, 1-5. doi: 10.1371/journal.pmed.1001769.

Tyrer R, Fazel M (2015). School and community-based interventions for refugee and asylum seeking children: a systematic review. PLOS ONE 9, 1-12. doi: 10.1371/journal. pone.0089359.

UNHCR (2015). Figures at a glance. Retrieved from http:// www.unhcr.org/pages/49c3646c11.html 